San Jose State University

SJSU ScholarWorks

Master's Theses

Master's Theses and Graduate Research

Summer 2015

\title{
The Interactive Effects of Accent, Attire, and Job Status on Employment-Related Decisions
}

Bonnie Nguyen

San Jose State University

Follow this and additional works at: https://scholarworks.sjsu.edu/etd_theses

\section{Recommended Citation}

Nguyen, Bonnie, "The Interactive Effects of Accent, Attire, and Job Status on Employment-Related Decisions" (2015). Master's Theses. 4605.

DOI: https://doi.org/10.31979/etd.byju-6c75

https://scholarworks.sjsu.edu/etd_theses/4605

This Thesis is brought to you for free and open access by the Master's Theses and Graduate Research at SJSU ScholarWorks. It has been accepted for inclusion in Master's Theses by an authorized administrator of SJSU ScholarWorks. For more information, please contact scholarworks@sjsu.edu. 


\title{
THE INTERACTIVE EFFECTS OF ACCENT, ATTIRE, AND JOB STATUS ON
} EMPLOYMENT-RELATED DECISIONS

\author{
A Thesis \\ Presented to \\ The Faculty of the Department of Psychology \\ San José State University \\ In Partial Fulfillment \\ of the Requirements for the Degree \\ Master of Science
}

by

Bonnie H. Nguyen

August 2015 
(C) 2015

Bonnie H. Nguyen

ALL RIGHTS RESERVED 
The Designated Thesis Committee Approves the Thesis Titled

THE INTERACTIVE EFFECTS OF ACCENT, ATTIRE, AND JOB STATUS ON EMPLOYMENT-RELATED DECISIONS

by

Bonnie H. Nguyen

APPROVED FOR THE DEPARTMENT OF PSYCHOLOGY

SAN JOSÉ STATE UNIVERSITY

\begin{abstract}
August 2015
Dr. Megumi Hosoda

Department of Psychology

Dr. Altovise Rogers

Department of Psychology

Mina Luong, M.S

Silicon Valley Bank
\end{abstract}




\title{
ABSTRACT \\ THE INTERACTIVE EFFECTS OF ACCENT, ATTIRE, AND JOB STATUS ON EMPLOYMENT-RELATED DECISIONS
}

\author{
by Bonnie H. Nguyen
}

Using data from 207 college students, the interactive effects of an applicant's accent (standard American English vs. Arabic), attire (no hijab vs. hijab), and job status (low vs. high) on perceived applicant characteristics (i.e., competence and warmth) and employment-related decisions (i.e., job suitability and hiring recommendation) were examined. Inconsistent with the hypotheses, results showed that an Arabic-accented and an applicant wearing a hijab were not rated as less competent and warm compared to a standard American-accented applicant and an applicant not wearing a hijab, respectively. Additionally, an Arabic-accented applicant wearing a hijab was not perceived as less competent and warm. However, when it came to employment-related decisions, an Arabic-accented applicant was considered less suitable for a low status job compared to a standard American English-accented applicant. When an applicant did not wear a hijab, an Arabic-accented applicant was rated less suitable for a high status job compared to a standard American English-accented applicant. A standard American English-accented applicant wearing a hijab was rated as less suitable compared to those not wearing a hijab for a high status job. The results of the study indicate that a foreign accent and hijab could serve as bases for stigma. Consequently, foreign-accented applicants and applicants who wear a hijab might suffer disadvantages in an employment setting. Organizational strategies such as job-structured interviews are discussed to minimize the negative impact of such stigmas. 


\section{ACKNOWLEDGEMENTS}

First, I would like to express my deepest gratitude to my thesis advisor, Dr. Megumi Hosoda for her support throughout my entire thesis process. She has been such a delight to collaborate with and her passion for research is inspirational. I am incredibly grateful for the time she invested to discuss challenges and successes with me. I could not have done this without her guidance. Thank you for your effort, enthusiasm, and mentorship.

Second, thank you Dr. Altovise Rogers for her incredible insight in research and I/O as a field. I greatly appreciate the many resources and suggestions that you have provided to me. I would also like to thank Mina for her positivity and encouragement from beginning to end of my thesis. Mina has really made this process a brighter experience for me through her infectious and loving personality.

Third, a very special thanks to my fiancé Edison for his constant support towards my academic goals. It has been a long road filled with sacrifices but I know it will be rewarding for us in the end. I greatly appreciate that you remained engaged and listened to me read my thesis aloud for many nights. You really helped me focus on my thesis even during some of the most challenging times. I am so fortunate to find a partner in life to keep me motivated and inspired to be my best.

Lastly, I would like to say thank you to my loving friends and family for their words of encouragement through some of the toughest times. My journey in life would be unfulfilling without all of your unwavering love and support. Thank you all for being my beacon of light in this world. I love you all! 


\section{TABLE OF CONTENTS}

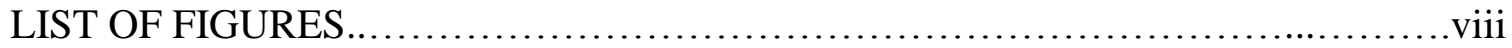

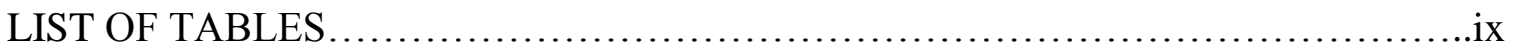

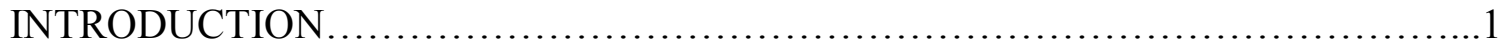

A Model of Stigmatization in Organizations...................................... 4

Literature Reviews on the Perceptions of Foreign Accented Individuals and Women

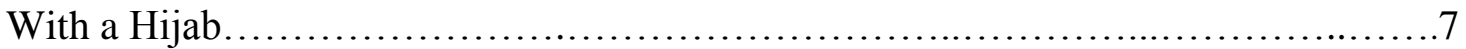

Perceptions of foreign-accented individuals ..................................

Perceptions of women with a hijab............................................

Effects of Foreign Accents and a hijab on Employment-Related Decisions.........10

Effects of foreign-accents on employment-related decisions...................10

Effects of a hijab on employment-related decisions............................13

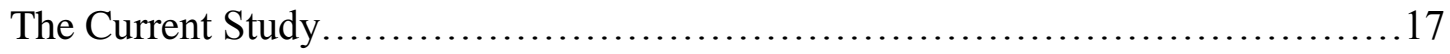

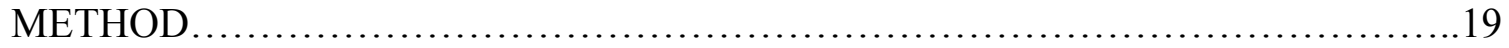

Participants..................................................................... 19

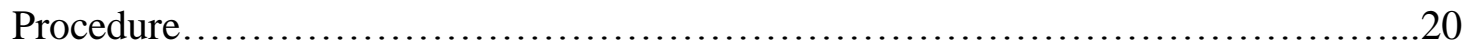

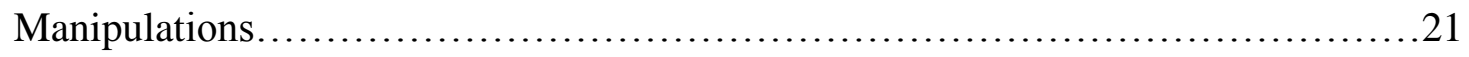

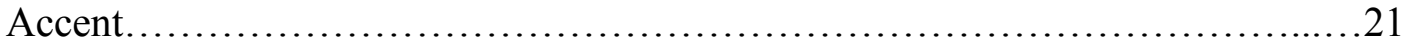

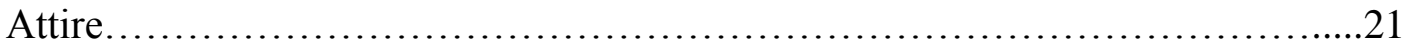

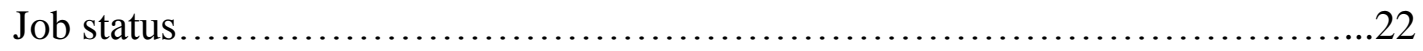

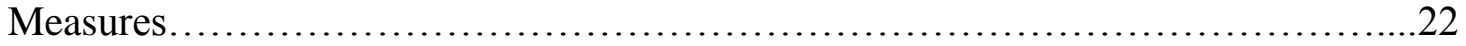

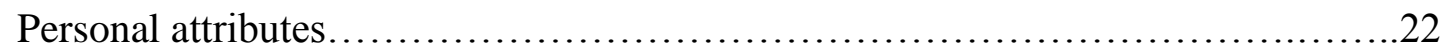


Job suitability......................................................22

Hiring recommendation................................................23

Demographic information................................................23

Manipulation checks.....................................................23

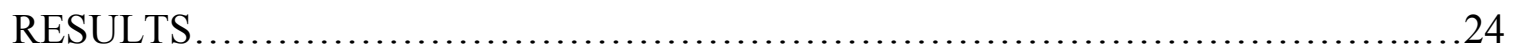

Manipulation Checks.....................................................24

Speaker accent......................................................... 24

Attire and job status.................................................. 24

Tests of Hypotheses and Research Questions....................................25

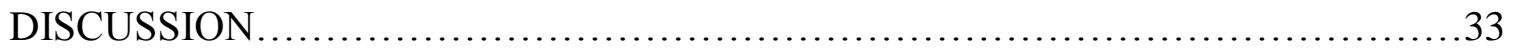

Theoretical Implications................................................ 37

Practical Implications................................................... 38

Strengths, Limitations, and Future Research.................................... 39

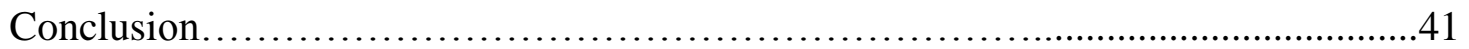

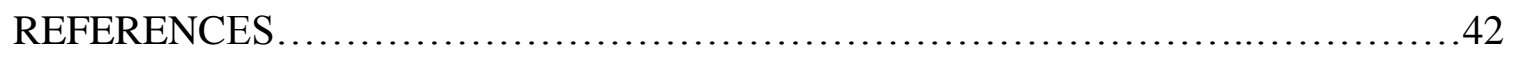

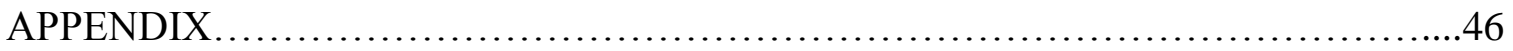

Survey Items........................................................46 


\section{LIST OF FIGURES}

Figure 1. Suitability Ratings as a Function of Accent, Hijab and Job Status............28

Figure 2. Hiring Recommendation as a Function of Accent and Job Status..............31 


\section{LIST OF TABLES}

TABLE 1: Means and Standard Deviations for Perceived Competence and Warmth as a Function of a Job Applicant's Accent, Attire, and Job Status...............26

TABLE 2: Means Suitability Ratings as a Function of a Job Applicant's Accent, Attire, and Job Status.........................................................

TABLE 3: Mean Job Suitability as a Function of a Job Applicant's Accent, Attire and Job

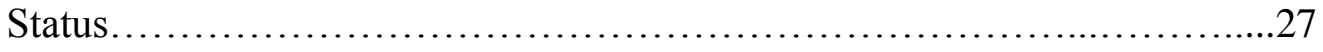

TABLE 4: Means and Standard Deviations for Hiring recommendations as a Function of a Job Applicant's Accent and Job Status.....................................30

TABLE 5: Mean Hiring Recommendation as a Function of a Job Applicant's Accent and

Job Status 30 


\section{Introduction}

Immigrants have contributed to the growth of the population in the United States. Currently, almost 40 million foreign-born individuals live in this country, comprising $13 \%$ of the population (U.S. Census Bureau, 2010). Immigrants also occupy a sizable proportion of the U.S. labor force, making up $16.5 \%$ of it, totaling 25.7 million foreignborn workers (U.S. Department of Labor, 2014). Although foreign-born workers play an important role in the U.S. economy, many immigrants face serious barriers to full participation in society (Podberesky, Deluty, \& Feldstein, 1990). For example, immigrants have much higher unemployment rates and much lower earnings than native English speakers (Reitz, 2001). The poverty rate is also much higher for immigrants than for native English speakers (19.9\% vs.13.5\%, respectively) (Center for Immigration Studies, 2011). Cargile and Bradac (2001) also argued that immigrants might continue to be disadvantaged because native English speakers often react negatively to their foreign accents. For example, in a survey of a nationwide stratified random sample of U.S. employers, $10 \%$ of them (i.e., 461,000 employers) reported that they engaged in discriminatory behavior based on a person's foreign appearance or accent (U.S. General Accounting Office, 1990).

Although Title VII of the Civil Rights Act of 1964 makes it illegal for an employer to make employment decisions based on national origin, the number of workplace discrimination complaints based on national origin, including those involving language ability and foreign accents, increased by 76\% from 1997 to 2011 (Post, 2012). Many of these complaints involve allegations of discrimination based on workers accent. 
For example, a truck driver sued FedEx claiming that he was wrongfully fired due to his Russian accent (Post, 2012). In another case, an Iraqi native who worked at a Four Points Sheraton reported that his co-workers mocked him because of his accent and complained that his supervisors did not take his claims seriously nor take the appropriate action to address the situation (Post, 2012). These examples provide that foreign-accented incumbents are likely to be discriminated against in the workplace.

Research on the effects of a foreign accent in the workplace has also shown that there is a bias against foreign-accented applicants (Hosoda, Nguyen, \& Stone-Romero, 2012). For example, Hosoda et al. found that standard American English-accented job applicants were rated as more suitable compared to Mexican-Spanish-accented applicants for a software engineering position. However, research on foreign accents in the workplace has exclusively been focused on the effects of foreign accents on employmentrelated decisions and has neglected to examine how other qualities of immigrants might interact with a foreign accent to influence employment-related decisions. Indeed, Deprez-Sims and Morris (2013) called for more studies that would explore the specific conditions under which accent-based bias occurs, such as the characteristics of a target with an accent, of decision makers, and of organizational contexts.

Given Deprez-Sims and Morris' assertion, this study explored the characteristics of a target with an accent, by specifically considering a hijab as a characteristic of foreign-accented individuals. A hijab is a Muslim headscarf that women wear based on religious obligations (Ghumman \& Ryan, 2013). In a survey conducted by the Pew Research Center (2007), it was estimated that about $51 \%$ of the female Muslim 
population in the U.S. wore a hijab all or some of the time. There is evidence that women with a hijab experience a bias in the workplace. For example, a clothing retailer Abercrombie \& Fitch was found to be guilty of wrongfully firing a Muslim worker who insisted on wearing her headscarf on the job (Caulifield, 2011). Unkelback, Schneider, Gode, and Senft (2010) also reported that women who wore a hijab and applied for an internship position at a company were more quickly rejected and more slowly accepted, compared to women not wearing hijabs.

This raises an interesting question. What if a woman who wears a hijab and speaks English with an Arabic accent applies for a job - how will she be evaluated? Unfortunately, little is known about how such a woman will be evaluated when applying for a job. Media portrayals of women who wear a hijab reveal numerous negative perceptions of them in the U.S and often times reduce their image to stereotypical portrayals of Muslim women. The 9/11 terrorist attacks have altered the way Americans perceive Islam and the way Muslims are treated (Lombardo, 2013) and Muslims are often perceived to be associated with terrorism or "the enemy." Those who display their religion more visibly are especially targeted, and a hijab is the most recognizable way to identify Islamic beliefs (Lombardo, 2013). Moreover, a hijab is seen as a hostile and confrontational political marker and a symbol of being a suspicious person rather than a religious choice (Lombardo, 2013). Therefore, it is likely that individuals who speak with an Arabic accent and wear a hijab are likely to face employment discrimination upon applying for a job. 
Thus, the present study was designed to examine how accent (standard AmericanEnglish vs. Arabic), attire (hijab vs. no hijab), and status of a sales job (high status vs. low status) would interact to influence employment-related decisions (e.g., suitability rating, hiring recommendation). To the author's best knowledge, this is the first study to include the additional attribute of immigrants beside a foreign accent and explore the joint effects of a foreign accent and the presence of a hijab in an employment context. In the following section, the model of stigmatization in organizations (Stone-Romero \& Stone, 2007) is discussed as the theoretical framework to explain the potential unfavorable treatment towards foreign-accented and/or those who wear a hijab. Literature on perceptions of foreign-accented individuals and of those with a hijab is reviewed, followed by a review of the effects of foreign-accents and a hijab on employment-related decisions. Finally, the hypotheses tested are presented.

\section{A Model of Stigmatization in Organizations}

Stone-Romero and Stone (2007), arguing that little research has examined stigmas in the fields of organizational behavior and industrial and organizational psychology, developed a model of stigmatization in the workplace. They define stigma as a real or perceived deeply discrediting discrepancy between a person's virtual and actual social identities (Stone-Romero \& Stone, 2007). A virtual social identity (VSI) represents what is expected of a person in terms of characteristics such as his or her abilities, personality, physical appearance, values, attitudes, and behaviors in a social system such as an organization. That is, a VSI represents the prototype of the ideal job applicant and/or employee and reflects how he or she should behave in an organizational context. On the 
other hand, an actual social identity (ASI) represents the way a person is actually perceived or is capable of being perceived by an observer. A person is said to be stigmatized or marked when his or her actual or stereotype-based attributes (i.e., ASI) are discrepant from normative standards (i.e., VSI). Consequently, job applicants and/or job incumbents are discredited by others (e.g., supervisors, peers, subordinates) due to the presence of stigmas (Stone-Romero \& Stone).

According to Stone-Romero and Stone (2007), organizational culture (e.g., its values and norms) greatly influences views about the VSIs of job applicants and/or incumbents. In most U.S. organizations, male, white, Anglo-Saxon Protestants (MWASPs), reflecting the dominant group in society, have greater potential to influence the culture of an organization than do minority group members (e.g., women, racial/ethnic minorities). Consequently, the prototypes of ideal job applicants and/or incumbents mirror the values and beliefs of MWASPs (Stone-Romero \& Stone). A VSI also reflects attributes such as race, ethnicity, and pronunciation. Thus, there will be a discrepancy between ASI and VSI among those with a foreign accent and/or hijab. Consequently, such individuals are likely to be stigmatized in an organization.

However, the prototypes of job applicants and/or incumbents (VSIs) typically vary as a function of job status (Stone-Romero \& Stone, 2007). For example, in U.S. organizations, the ideal prototypical applicant or incumbent for a high status role (e.g., jobs) typically represents characteristics that are similar to those of the dominant group in society (e.g., young, attractive, tall, physically fit, heterosexual, male, white, AngloSaxon, Christian)(Stone-Romero \& Stone). Consequently, members of the non-dominant 
group (e.g., female, racial/ethnic minority, immigrants, those who wear a hijab) experience the discrepancy between the VSI and ASI and are often perceived as unsuitable for high status jobs. However, the prototypes of incumbents for a low status role are similar to the ASIs of non-dominant groups. Therefore, individuals who have an accent and wear a hijab are likely to be preferred for low status jobs (Stone-Romero \& Stone).

An important consequence of an individual's ASI is that it serves as the basis for a decision maker's cognitions. That is, decision makers categorize an individual based on his or her salient attributes (e.g., physical disability, race, appearance, accent, and hijab). Such categorization activates the stereotype associated with the social category and the decision makers use those stereotypes to draw inferences about the individuals' attributes (e.g., intelligence, interpersonal skills, task performance) (Stone-Romero \& Stone, 2007). Thus, these stereotype-based inferences often play an important role in various human resources management (HRM) processes and practices (e.g., recruitment, selection, promotion). Hence, the treatment of an individual is mainly a result of the decision maker's cognitive responses to him or her. Simply put, how an individual is treated is determined largely by various stigmas and other factors that are not directly related to his or her job performance (Stone-Romero \& Stone, 2007). Consequently, stigmatized job applicants and/or incumbents are at a disadvantage in access-related (e.g., reduced chances of being hired for various types of jobs) and/or treatment-related (e.g., reduced likelihood of being promoted to upper level positions) decision making. The 
following section reviews the literature on how foreign-accented individuals and on how a hijab are perceived by others.

\section{Literature Reviews on the Perceptions of Foreign Accented Individuals and Women With a Hijab}

Perceptions of foreign-accented individuals. An accent is one salient characteristic of an individual and conveys a considerable amount of social information (Gluszek \& Dovidio, 2010). When an individual is categorized on the basis of an accent, it activates a wide range of negative stereotypic perceptions (Gluszek \& Dovidio). For example, a study by Brennan and Brennan (1981) revealed that standard American English accent was rated more favorably compared to Mexican-American accents on dimensions of social attractiveness and solidarity. Hosoda, Stone-Romero, and Walter (2007) also found that compared to standard American English-accented speakers, Asianaccented English speakers were perceived as poorer communicators and less potent on social status. In addition, Giles, Wilson, and Conway (1981) found that listeners rated standard-accented (Received Pronunciation) speakers as more aggressive, statusful, generous, and good-natured compared to South Welsh-accented speakers.

Barona (2008) examined how Spanish, Arabic, and Korean accents were evaluated by listeners in comparison to standard American English accent. Listeners were asked to provide their first impression of each accented-speaker's personality. Results showed that among those accented-speakers, native standard American Englishaccented speakers were rated most positively on competence, integrity, and social attractiveness. When differences in the evaluations of the three foreign accents were examined, the Arabic accent was rated lowest on competence (e.g., ambitious, 
intelligent), integrity (e.g., honest, reliable), and social attractiveness (e.g., friendly, likeable). The most negative perceptions of the Arabic-accent was probably due to stereotypes attached to the Arab community and the negative perceptions of them as a result of the 9/11 attacks and current feuds in the Middle-East (Lombardo, 2013).

More recently, Fuertes, Gottdiener, Martin, Gilbert, and Giles (2012) conducted a meta-analysis on the effects of speakers' accents on social evaluations and showed that standard-accented speakers were evaluated more favorably on status (e.g., intelligence, social class), solidarity (trustworthiness, in-group vs. out-group), and dynamism (level of activity and liveliness) dimensions than non-standard-accented speakers. In addition, results showed that standard-accented speakers were rated significantly higher than nonstandard-accented speakers in education $(d=.40)$, employment $(d=.53)$, and sales $(d=$ 1.59) settings. Based on these findings, Fuertes et al. have concluded that decision makers perceive an accent as an immediate marker to devalue non-standard-accented speakers and that an accent represents nothing but a considerable handicap.

Furthermore, Fiske, Cuddy, and Glick, and Xu (2002) have argued that stereotypes are measured by two universal dimensions (competence and warmth). Individuals attribute competence to the members of groups that are perceived as holding prestigious jobs and being economically successful, but they attribute warmth to the members of groups that are perceived to be harmless. They found that Arabs were characterized as lower on both competence and warmth dimensions than Americans (Fiske et al., 2002; Lee \& Fiske, 2006). Given these findings, it was expected that 
Arabic-accented job applicants would be rated lower than standard American Englishaccented applicants on both dimensions.

Hypothesis 1: Arabic-accented applicants will be perceived less positively on competence (e.g., competence, status) and warmth (e.g., kind, friendly) than standard American English-accented applicants.

Perceptions of women with a hijab. A hijab or the head-covering piece has emerged as a highly salient symbol for Muslim women's identity in recent years (Mahmud \& Swami, 2010). Thus, women wearing hijabs are easily categorized as Muslim, which activates possible stereotypes and prejudices associated with the Muslim religion (Unkelbach et al., 2010). To date, there are only a few studies that have examined the perception of women who wear a hijab. For example, Mahmud and Swami (2010) examined the effects of wearing a hijab on perceptions of women by British men. They hypothesized that wearing a hijab would result in more negative ratings of attractiveness and intelligence. Consistent with the hypothesis, results showed that women wearing a hijab were rated as significantly less attractive and less intelligent than women not wearing a hijab. Although their measures did not include competence and warmth dimensions, intelligence can be thought of as part of the competence dimension and attractiveness can be considered part of the warmth dimension. Furthermore, King and Ahmad (2010) also showed that Muslim women were perceived less positively (e.g., friendly, good-natured) compared to women who did not appear to be Muslim.

Given these findings, the following was hypothesized: 
Hypothesis 2: Applicants who wear a hijab will be perceived less favorably on competence (e.g., competence, status) and warmth (e.g., kind, friendly) than non-hijab applicants.

Both literatures on foreign-accented individuals and those who wear a hijab have revealed unfavorable perceptions against them independently, compared to standard speakers and who do not wear a hijab, respectively. Thus, the combination of such salient attributes of an individual is likely to make them more susceptible to negative evaluations compared to standard American English-accented speakers without a hijab. Therefore, the following was hypothesized:

Hypothesis 3: There will be an interaction between accent (standard American English vs. Arabic) and attire (hijab vs. no hijab) on the perceptions of competence and warmth such that Arabic-accented applicants with a hijab will be evaluated least positively on competence (e.g., competence, status) and warmth (e.g., kind, friendly) and standard American English-accented applicant without a hijab will be rated most favorably on these dimensions.

The following section reviews a literature on the effects of foreign accents and of a hijab on employment-related decisions.

\section{Effects of Foreign Accents and a Hijab on Employment-Related Decisions Effects of foreign-accents on employment-related decisions. As mentioned earlier, Fuertes et al. (2012) reported that standard-accented speakers were rated more positively than non-standard-accented speakers in a variety of settings, including employment and sales settings. In particular, the effect size associated with employment}


was moderate $(\mathrm{d}=.53)$ but the effect size associated with sales was strong $(\mathrm{d}=1.59)$. These findings demonstrate that accented individuals are clearly at a disadvantage in the workplace, in particular in sales jobs. Overall, these findings reveal the potential negative consequences that non-standard-accented speakers may face in the workplace.

A number of studies have examined the effects of foreign accents on employment-related decisions and findings have shown that there is a bias against foreign-accented applicants, especially for high status jobs. For example, Hosoda et al. (2012) examined the effects of the accent (standard American English and Mexican Spanish) of a hypothetical job applicant on job suitability ratings and hiring decisions for an entry-level software engineering job (high status job). More specifically, participants were asked to listen to either a Mexican-Spanish-accented job applicant or a standard American English-accented job applicant describing his desire for the job and to make employment-related decisions (i.e., job suitability ratings, likelihood of a promotion, and hiring decision). Results showed that the Mexican-Spanish accented applicant was rated as less suitable for the job, viewed as less likely to be promoted to a managerial position. In addition, fewer participants made the decision to hire the Mexican-Spanish-accented applicant compared to the standard American English-accented applicant.

Furthermore, Kalin, Rayko, and Love (1980) examined the effects of four accents (English, German, West Indian, and South Asian) on job suitability for four jobs that varied in status from low to high. These four jobs were industrial plant cleaner, production assembler, industrial mechanic, and foreman. Results showed that for the higher status job (foreman), English-accented candidates were rated as most suitable, 
followed by German-accented, South Asian-accented, and finally West Indian-accented candidates. For the lowest status job, (industrial plant cleaner), the order was exactly reversed such that West Indian-accented candidates were rated as most suitable, followed by South Asian-accented, German-accented, and English-accented candidates. Similarly, Giles, Wilson, and Conway (1981) examined a standard accent (Received Pronunciation) versus a non-standard accent (South Welsh accent) of a hypothetical job applicant on perceived job suitability. Participants were asked to act as a personnel consultant and rate the applicants' suitability for each of four jobs that varied on status. They used the same job types as did Kalin et al. Results revealed an interaction effect between accent type and job status such that the three low status jobs (i.e., industrial plant cleaner, production assembler, and industrial mechanic) were seen as more suitable for South Welsh English-accented applicants than for those with Received Pronunciation (RP) accent. Interestingly, standard-accented speakers were not considered entirely more suitable for the high status job (i.e., foreman).

However, in Deprez-Sims and Morris (2010), participants were asked to listen to an applicant with one of three accents (Midwestern US, French, and Colombian) during an interview for a male applicant for a human resource manager position. Participants were asked to rate him on the suitability for the job and make a hiring recommendation. Results revealed that although there were no significant differences on hiring recommendations among these three accents, the Midwestern U.S accent received higher ratings on hirability compared to the French and Colombian applicants. Moreover, the 
Columbian-accented and Midwestern U.S.-accented applicants were rated higher than the French applicant on suitability ratings.

In sum, with the exception of Deprez-Sims and Morris (2010), the above findings clearly indicate that the overall effects of foreign accents on employment-related decisions depend on the status of a job such that non-standard-accented applicants are evaluated more positively for lower status jobs than for higher status jobs, and the opposite is true for standard-accented applicants. Therefore, in line with the model of stigmatization, an applicant who speaks with a non-standard accent is likely to be evaluated more negatively, especially for high status jobs, compared to standard-accented individuals. The following section reviews the literature of the effects of a hijab on employment-related decisions.

Effects of a hijab on employment-related decisions. Although research on the impact of a hijab on employment-related decisions is scarce, available evidence demonstrates that those who wear a hijab are consistently discriminated against. To illustrate, Ghumman and Ryan (2013) conducted a field experiment to examine potential discrimination against individuals who wore a hijab. To ensure that results would generalize to a wide variety of Muslim women, six South Asian, one Middle Eastern, two Black, and five Caucasian female undergraduates acted as job applicants. They applied for a job in retail stores and restaurants that were matched in terms of typical clientele, primarily geared towards a low to middle-income level clientele. In addition, another 14 female college students served as observers for each confederate. Half of the confederates wore a hijab (plain black headscarf) and the other half wore no hijab 
(control condition). Results showed that those with hijabs experienced both interpersonal and formal discrimination. More specifically, compared to those without hijabs, those with hijabs were less likely to receive call backs and permission to complete job applications from the potential employers. In addition, those with hijabs experienced more negative interpersonal behaviors from the potential employers, including being less helpful, more hostile or more standoffish, avoiding eye contact more, ending conversations more prematurely, and showing less interest when interacting with them. Similarly, a study by Unkelbach et al. (2010) demonstrated bias against women wearing hijabs. They manipulated the presence of a hijab (hijab vs. no hijab), ethnicity (Caucasian vs. non-Caucasian), and academic achievement (mediocre vs. good vs. excellent) of potential job applicants. It was hypothesized that wearing hijabs would lead to lower acceptance rates upon reviewing applicant applications. It was also hypothesized that wearing a hijab would interact with the applicants' ethnicity. Information about applicants' academic information, followed by a picture of each applicant was provided for participants to view. Participants were asked to make fast decisions on whether to "keep" versus "reject" applicants, who were applying for an internship position. No objective criteria about applicants were provided other than their academic information (i.e., grades), because they hypothesized that this uncertainty would possibly bias participants against those wearing hijabs.

Results showed a main effect for a hijab such that those wearing a hijab were rejected more often than those not wearing a hijab. There was an interaction effect between the ethnicity of applicants and the presence of a hijab. That is, the negative 
effect of wearing a hijab was amplified for the Caucasian compared to non-Caucasian applicants. In other words, Caucasian applicants who wore a hijab were rejected most often. According to Unkelbach et al. (2010), there are two possible reasons for the more negative evaluations of Caucasian women with hijabs. First, the contrast of Caucasian ethnicity and wearing a hijab might make a hijab a more prominent feature. Second, participants might have perceived Caucasian women wearing a hijab as converts, which might have triggered existing fears about Islamic culture that "Islamic culture tries to change the world according to its rule instead of assimilating and integrating with existing Western cultures" (p. 381). Overall, results showed a bias against Muslims despite objective information (e.g., excellent academic performance) such that participants rejected women wearing hijabs, especially if women were Caucasian. This was true, regardless of their objective academic achievement.

Furthermore, King and Ahmad (2010) conducted a field experiment to examine employers' interpersonal treatment towards Muslim job applicants. The study used a 2 (religion: Muslim vs. control) x 2 (behavior: warm vs. control) between-subjects design. They hypothesized that those who appeared to be Muslim would encounter more interpersonal discrimination compared to those who did not appear to be Muslim upon applying for a job. They also hypothesized that the effect of a Muslim identity on interpersonal discrimination would be attenuated by including stereotypically inconsistent information (i.e., warmth) such that job applicants who appeared to be Muslim and did not have stereotype-inconsistent information would be more likely to experience interpersonal discrimination than applicants in any other conditions. Warmth 
(stereotypically inconsistent information) was manipulated as providing past volunteer experience. The study involved three sets of individuals: confederate job applicants, observers, and coders. Confederates consisted of women of various backgrounds (one Caucasian, one South Asian, and one Middle Eastern) between 20 and 25 years of age. Observers included five individuals from various ethnic backgrounds. Lastly, two undergraduates who were not informed of the experimental conditions listened to and coded the audiotape recordings of interactions between job applicants and store managers. Interpersonal discrimination was measured, which included behavioral cues from managers based on their enthusiasm, distance, nodding and affirmative gestures, smiling, and helpfulness toward the job applicant. Results showed that job applicants who wore a hijab and did not provide stereotype-inconsistent information experienced more interpersonal discrimination (e.g., rudeness, hostility) compared to those who did not appear Muslim. Specifically, confederate applicants and observers rated interactions with store managers more negatively when the confederate applicants wore a hijab than when they did not wear such attire. In addition, store managers spent less time interacting with the applicants who appeared to be Muslim than those who did not. It is noteworthy that Muslim applicants who displayed warmth were rated similarly to nonMuslim job applicants. Such findings suggest that a Muslim applicant who did not counteract stereotypes such as lacking warmth is subtly discriminated against.

To date, no studies have looked at the joint effect of an accent and attire in an employment context. Although foreign-accented and those who wear a hijab have been evaluated less positively on hiring decisions, there are no studies that have examined the 
joint effect of accent and hijab on hiring decisions. Thus, the following research questions were posited:

Research Question 1: Will the accent and attire of job applicants, and job status interact to influence a job suitability rating?

Research Question 2: Will the accent and attire of job applicants, and job status interact to influence a recommendation for hiring?

\section{The Current Study}

Research on the impact of accents on employment-related decisions clearly shows bias against foreign-accented applicants, especially for high status jobs. Likewise, research on the impact of a hijab on employment-related decisions shows that those who wear a hijab are likely to be discriminated against when they apply for a job. An important gap in the research on the effects of accents on employment-related decision is the lack of attention to the factors other than accents that might affect employmentrelated decisions.

As mentioned earlier, both accent and a hijab are salient attributes of an individual which are likely to evoke the stereotypes associated with its respective social group and might interactively influence employment-related decisions. Although a number of studies have demonstrated negative perceptions and unfavorable treatment of those with foreign accents and those who wear a hijab when they are considered independently, to the author's best knowledge, there are no studies that have examined the interactive effects of an accent and a hijab on employment-related decisions. Both an accent and hijab are audio and visual cues of an individual, respectively, making them more 
susceptible to bias and prejudice upon interaction with decision makers. Interestingly, social psychologists have so far largely ignored the topic pertaining to a hijab (Unkelbach et al., 2010). This is also true for industrial and organizational psychologists. Therefore, to extend research on an understudied topic, this study was designed to expand knowledge on women who speak English with an accent and who wear a hijab upon interviewing for a job. Thus, the present study fills a gap in the literature by including an additional salient marker (i.e., a hijab) of foreign-accented individuals on perceptions and a hiring recommendation.

Therefore, the present study examined the interactive effect of accent (standard American English vs. Arabic), attire (hijab vs. no hijab) and status of a retail sales job (low status vs. high status) on personal attributes, suitability ratings and hiring decisions. A retail sales job was chosen because of the nature of the job (e.g., high interface and communication with customers). This is the first study to examine the combined effect of accent, a hijab, and status of a retail sales job upon employment-related decisions and addresses the important concern of the discrimination that immigrants may face upon interviewing for a job. 


\section{Method}

\section{Participants}

A total of 255 undergraduate students from a large state university in Northern California participated in the study as part of course requirements or extra credit opportunities. Data from 48 participants were deleted from further analyses because 15 participants were younger than 18 years old and 33 participants failed the manipulation check.

Therefore, the final sample consisted of 207 participants (82 male and 125 female). Their ages ranged from 18 years to 62 years $(M=20.07, S D=4.23)$. The sample was diverse in terms of its ethnic composition: $37.7 \%$ Asian $(n=78), 23.2 \%$ Latino/a $(n=48), 17.9 \%$ White $(n=37), 10.6 \%$ mixed ethnicity $(n=22), 6.8 \%$ other $(n=$ 14), and 3.9\% African American $(n=8)$. When asked what language they spoke at home, $44.2 \%(n=92)$ of participants reported that they spoke English only, $41.3 \%(n=$ 84) reported that they spoke both English and another language, and 14.1\% $(n=29)$ reported that they spoke a language other than English. More than 65.2\% $(n=133)$ of respondents reported living in a multilingual home. A total of $65.7 \%(n=137)$ reported having a family member who spoke with a foreign accent. A total of $60.4 \%$ participants were working at the time of data collection. Among them, 55.6\% were working part time and $4.8 \%$ working full time. A total of $91.3 \%(n=189)$ respondents reported having work experience $(M=2.59$ years, $S D=3.59)$. Lastly, a total of $30.2 \%(n=62)$ of participants reported they had worked in retail. 


\section{Procedure}

Each experimental session was conducted with a small group of participants (ranging from one to six). Participants were led into a room and were provided with the consent form to read and sign. At the beginning of each session, an experimenter informed participants that the study was about the evaluation and hiring decisions of a hypothetical job candidate. The experimenter read the instructions aloud while the participants followed along with the paper they had been handed. Participants were then asked to place themselves in the position of a hiring manager and were instructed to evaluate the applicant's information and interview carefully. Afterwards, participants were provided with the description of a retail store, job qualifications of the sales position, a resume, and a photo of the hypothetical job applicant whom they were about to view and hear on the laptop. They were given about two to three minutes to read the materials while the experimenter stepped outside.

The experimenter then informed them that they would listen to the recording of an interview for a retail sales associate position. A laptop was positioned across the table from the participants, with the photo of the applicant on the screen facing towards them. The experimenter then started the audio playback on the laptop and left the room. After the recording finished, the experimenter returned to the room and distributed the questionnaire which was designed to measure (a) the personal attributes of the job applicant, (b) the suitability for the sales position, (c) a hiring recommendation, and (d) demographic information. The experimenter exited the room while participants completed the questionnaire. Upon completion of the questionnaire, they were given a 
debriefing sheet that explained the purpose of the experiment. Participants were randomly assigned to one of the eight experimental conditions that differed in accent (standard American English vs. Arabic), attire (hijab vs. no hijab), and status of a retail store (high status vs. low status).

\section{Manipulations}

Accent. A matched-guise technique (Lambert, 1967) was used to manipulate the accent of a hypothetical job applicant, in which a single, bilingual Arabic-American speaker read a prepared script for a hypothetical job interview in two different accents (standard American English and Arabic). This technique is widely used because the speaker's linguistic characteristics are held constant (e.g., voice pitch, tone, rate) across different accent conditions, thereby ruling out various confounds (Bresnahan, Ohashi, Nebashi, Liu, \& Shearman, 2002). Multiple recordings of the speaker were produced in order for the speaker to familiarize her with the script and sound more natural before selection of the most suitable audio recording version. The speaker was fluent in English and used correct grammar. The interview recording lasted for two minutes.

Attire. Full-face color photographs of a Caucasian female were captured under room lighting with a white background. Both conditions used the photograph of the same female (with hijab and without hijab). For both conditions, her facial expression displayed a slight smile with her mouth closed. In the hijab condition, the female was wearing a white scarf covering her hair, neck and shoulders. In the no-hijab condition, the female's hair was displayed but pulled back from the face, and she wore a white scarf over her shoulders. 
Job status. Two different descriptions of a retail store (low status vs. high status) were created in order to manipulate job status. A low status retail store was described as a women's clothing retailer that carried low budget yet fashionable merchandise such as accessories, handbags, and clothing and it operated in a variety of malls throughout the United States. In contrast, a high status retail store was described as a high status French fashion house that specialized in products such as couture, clothing, accessories, and luxury goods.

\section{Measures}

Personal attributes. Personal attributes of the hypothetical employee were measured in terms of perceived competence (seven items, $\alpha=.73$ ) and perceived warmth (seven items, $\alpha=.93$ ). Each of these variables was measured using semantic differential items that had seven equally-spaced line segments. The higher the score on the measure, the more positively the speaker was perceived. Sample items are "lower class - upper class" and "unintelligent - intelligent" for perceived competence, and "cold - warm" and "unfriendly - friendly" for perceived warmth.

Job suitability. Job suitability was measured with a 12 -item scale $(\alpha=.94)$. Sample items are "The applicant is qualified for the job" and "The applicant will be successful on the job." Participants responded to these items using a 7-point Likert scale $(1=$ strongly disagree, $7=$ strongly agree $)$. The items were summed and averaged. The higher the score, the more suitable the applicant was rated for the job.

Hiring recommendation. Hiring recommendation was measured with one item. Participants were asked to indicate the degree to which they would recommend the job 
applicant for the job with a 7-point Likert scale $(1=$ Definitely would not recommend, $7=$ Definitely would recommend).

Demographic information. Participants were asked their sex, age, and race/ethnicity. Participants were also asked what language(s) they spoke at home, whether they lived in a multilingual home (yes or no), and whether a family member spoke English with an accent (yes or no). Furthermore, participants were asked whether they were working at the time of data collection, their employment status (part-time, fulltime), the number of years worked, and whether they had retail experience.

Manipulation checks. Four items were used to evaluate the effectiveness of the accent manipulation $(\alpha=.78)$. Participants were asked to rate the strength of the applicant's accent using a 7-point Likert scale $(1=$ no accent at all, $7=$ very strong accent). Participants were also asked to indicate their perception of the job applicant's race/ethnicity. To evaluate the effectiveness of attire and job status manipulations, participants were also asked to indicate whether the speaker had worn a headscarf (yes, no, or don't know), as well as the status of the retail store (high, low, or don't know). 


\section{Results}

\section{Manipulation Checks}

Speaker accent. The result of a 2 (accent: standard American English vs. Arabic) x 2 (attire: hijab vs. no hijab) x 2 (job status: low vs. high) analysis of variance (ANOVA) supported the effectiveness of the applicant accent manipulation. Only the main effect of the applicant accent was found, $F(1,200)=278.16, p<.001$. The Arabicaccented applicant was perceived as having a stronger accent $(M=4.02, S D=.86)$ than the standard American English-accented applicant $(M=1.95, S D=.89)$. Participants were also asked for their perception of the ethnicity of the job applicants. When participants were exposed to the standard American English-accented applicant, the percentage of participants who identified her as White ranged from $8.7 \%$ to $63.3 \%$. When the standard American English-accented applicant did not wear a hijab, $60 \%$ of the participants identified her as White. However, when the standard American Englishaccented applicant wore a hijab, about $71 \%$ of participants thought that she was Middle Eastern. When participants were exposed to the Arabic-accented job applicant, the percentage of participants correctly identifying the applicant as Middle Eastern ranged from $79.2 \%$ to $96.4 \%$.

Attire and job status. As mentioned earlier, data from the respondents who were incorrect on the hijab and/or status manipulation checks were deleted from further analyses. Data from the respondents who reported "don't know" for the hijab and/or status manipulation checks were included because statistical comparisons of those who responded "don't know" on either manipulation checks or both with those who were 
correct on these manipulation checks on the measured variables showed no difference between these groups.

\section{Tests of Hypotheses and Research Questions}

All the analyses were tested using a Type I error rate of .05. However, because an interaction effect is relatively hard to find, it was tested with a Type I error rate of .10 (Stone-Romero \& Liakhovitski, 2002).

Hypothesis 1 stated an Arabic-accented applicant would be perceived less positively on competence (e.g., competence, status) and warmth (e.g., kind, friendly) than a standard American English-accented applicant. Hypothesis 2 stated an applicant who wore a hijab would be perceived less favorably on competence (e.g., competence, status) and warmth (e.g., kind, friendly) than an applicant who did not wear a hijab. Hypothesis 3 stated that there would be an interaction between accent (standard American English vs. Arabic) and attire (hijab vs. no hijab) on the perceptions of competence and warmth such that an Arabic-accented applicant with a hijab would be evaluated least positively on competence (e.g., competence, status) and warmth (e.g., kind, friendly) and a standard American English-accented applicant without a hijab would be rated most favorably on these dimensions.

These hypotheses were tested with a 2 (accent) x 2 (attire) x 2 (job status)

multivariate analysis of variance (MANOVA). Results showed no main effect for accent, $F(2,180)=2.43, p=.091$, Wilks $\lambda=.97$ and for attire, $F(2,180)=.07, p=.93$, Wilks $\lambda$ $=.100$, nor an interaction between the two, $F(2,180)=2.33, p=.101$, Wilks $\lambda=.98$. These results show no support for Hypothesis 1 through 3. Table 1 presents the means 
and standard deviations for perceived competence and warmth as a function of a job applicant's accent, attire, and job status.

Table 1

Means and Standard Deviations for Perceived Competence and Warmth as a Function of a Job Applicant's Accent, Attire, and Job Status

\begin{tabular}{|c|c|c|c|c|c|c|c|c|c|c|c|c|}
\hline & \multicolumn{6}{|c|}{ Low-Status } & \multicolumn{6}{|c|}{ High-Status } \\
\hline & \multicolumn{3}{|c|}{ No Hijab } & \multicolumn{3}{|c|}{$\mathrm{Hijab}$} & \multicolumn{3}{|c|}{ No Hijab } & \multicolumn{3}{|c|}{$\mathrm{Hijab}$} \\
\hline & $n$ & $M$ & $S D$ & $n$ & $M$ & $S D$ & $n$ & $M$ & $S D$ & $n$ & $M$ & $S D$ \\
\hline & \multicolumn{12}{|c|}{ Competence } \\
\hline English & 22 & 5.56 & 0.65 & 22 & 5.10 & 0.65 & 29 & 5.24 & 0.84 & 29 & 5.35 & 0.71 \\
\hline Arabic & 17 & 4.81 & 0.92 & 24 & 5.21 & 0.65 & 21 & 5.10 & 0.58 & 25 & 5.19 & 0.74 \\
\hline & \multicolumn{12}{|c|}{ Warmth } \\
\hline \multicolumn{13}{|l|}{$\begin{array}{l}\text { Standard } \\
\text { American }\end{array}$} \\
\hline $\begin{array}{l}\text { Amencan } \\
\text { English }\end{array}$ & 22 & 5.91 & 1.03 & 22 & 5.49 & 1.45 & 29 & 5.72 & 1.00 & 29 & 5.89 & 0.98 \\
\hline Arabic & 17 & 5.25 & 1.11 & 24 & 5.47 & 1.05 & 21 & 5.60 & 0.94 & 25 & 5.61 & 0.96 \\
\hline
\end{tabular}

Research question 1 asked whether a job applicant's accent, attire, and job status interactively would influence decision makers' job suitability ratings of the applicant. A 2 (accent) $\times 2$ (attire) $\times 2$ (job status) ANOVA was used to test the research question. Table 2 displays the mean suitability ratings as a function of a job applicant's accent, attire, and job status. Results of the ANOVA showed that a main effect for accent was marginally significant, $F(1,199)=3.61, p=.059$, and there was a significant three-way interaction among accent, attire, and job status, $F(1,199)=4.31, p=.039$. Table 3 shows the summary of the ANOVA. Figure 1 shows the mean job suitability as a function of accent, hijab, and job status. 
Table 2

Mean Suitability Ratings as a Function of a Job Applicant's Accent, Attire, and Job Status

\begin{tabular}{|c|c|c|c|c|c|c|c|c|c|c|c|c|}
\hline & \multicolumn{6}{|c|}{ Low-Status } & \multicolumn{6}{|c|}{ High-Status } \\
\hline & \multicolumn{3}{|c|}{ No Hijab } & \multicolumn{3}{|c|}{ Hijab } & \multicolumn{3}{|c|}{ No Hijab } & \multicolumn{3}{|c|}{ Hijab } \\
\hline & $n$ & $M$ & $S D$ & $n$ & $M$ & $S D$ & $n$ & $M$ & $S D$ & $n$ & $M$ & $S D$ \\
\hline $\begin{array}{l}\text { Standard } \\
\text { American }\end{array}$ & & & & & & & & & & & & \\
\hline English & 28 & 5.76 & 1.23 & 23 & 6.11 & 0.68 & 30 & 5.93 & 0.85 & 30 & 5.44 & 1.45 \\
\hline Arabic & 19 & 5.57 & 0.74 & 25 & 5.49 & 0.87 & 24 & 5.43 & 1.05 & 28 & 5.68 & 0.69 \\
\hline
\end{tabular}

Table 3

Mean Job Suitability as a Function of a Job Applicant's Accent, Attire and Job Status

\begin{tabular}{lcccc}
\multicolumn{1}{c}{ Source } & $S S$ & $d f$ & $M S$ & $F$ \\
\hline Accent & 3.61 & 1 & 3.61 & 3.61 \\
Hijab & .00 & 1 & .00 & .00 \\
Job status & .61 & 1 & .61 & .61 \\
Accent x Hijab & .31 & 1 & .31 & .31 \\
Accent x Job status & .99 & 1 & .99 & .99 \\
Hijab x Job status & .85 & 1 & 4.3 & 4.31 \\
Accent x Hijab x Job status & 4.3 & 1 & 4.3 & $4.31^{*}$ \\
Error & & & & \\
\hline
\end{tabular}

note. $* p<.05$. 
Low status job

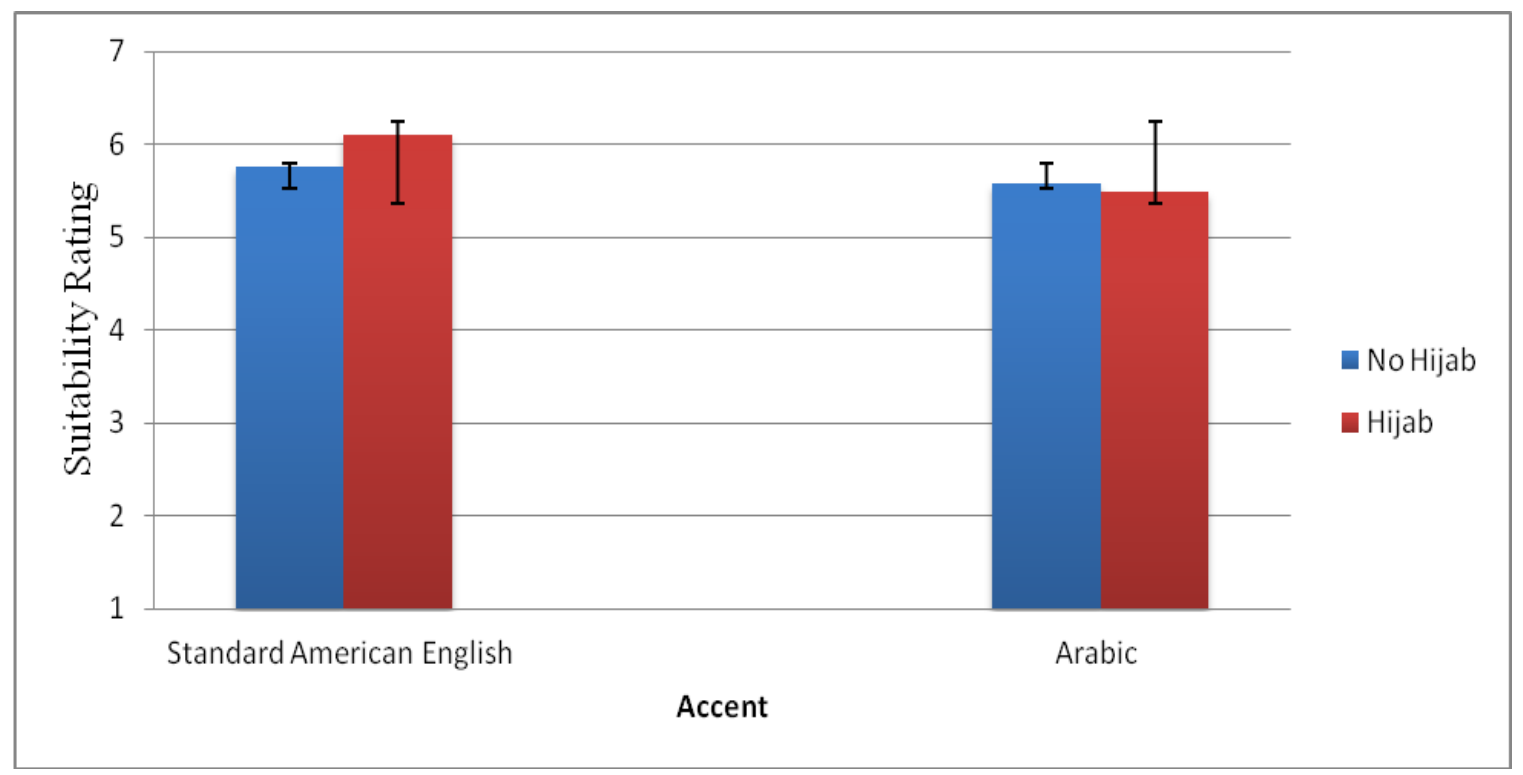

High status job

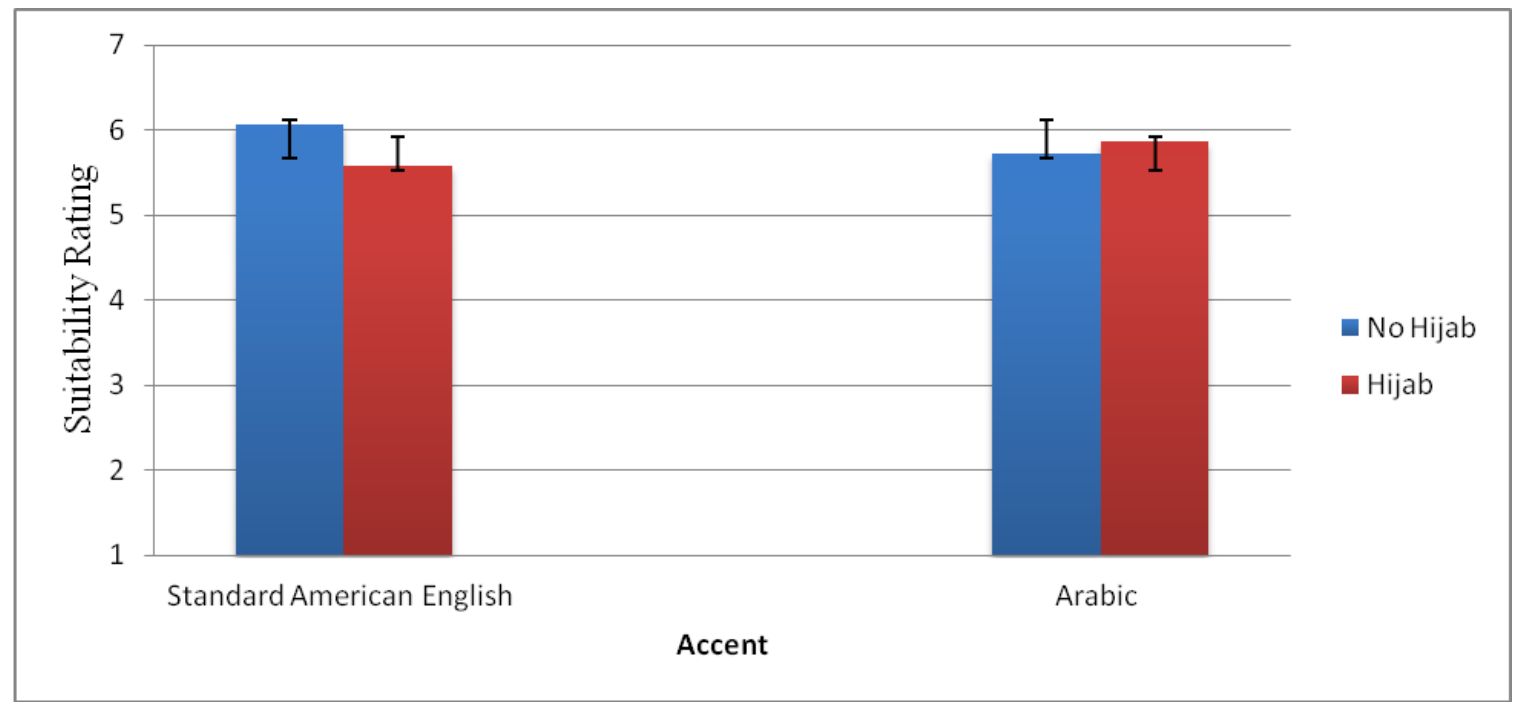

Figure 1. Suitability ratings as a function of accent, hijab and job status

A main effect for an applicant's accent showed that an Arabic-accented applicant $(M=5.55, S D=.84)$ tended to be rated as less suitable for the sales job than a standard English-accented applicant $(M=5.79, S D=1.13)$. Further analyses were conducted to 
analyze the significant three-way interaction. Results showed that in the low status condition, there was only a main effect of accent, $F(1,91)=4.44, \mathrm{p}=.038$, such that the standard American English-accented job applicant $(M=5.92, S D=1.02)$ was rated as more suitable compared to the Arabic-accented applicant $(M=5.52, S D=.81)$.

However, in the high status condition, there was an interaction between accent and attire, $F(1,112)=3.42, \mathrm{p}=.067$. Results of simple effects analyses showed the marginally significant effect of an applicant's accent, $F(1,108)=3.15, \mathrm{p}=.079$ such that the applicant with standard American English accent $(M=5.93, S D=.85)$ tended to be rated as more suitable compared to the Arabic-accented applicant $(M=5.43, S D=1.05)$ when they did not wear a hijab. Furthermore, there was the marginally significant effect of attire when the job applicant spoke with a standard American English accent, $F(1,108)=$ $3.27, \mathrm{p}=.073$, such that she was rated as more suitable for the job when she did not wear a hijab $(M=5.93, S D=.85)$ than when she wore a hijab $(M=5.44, S D=1.45)$.

Research question 2 asked whether a job applicant's accent, attire, and job status interactively would influence decision makers' hiring recommendations for the applicant. A 2 (accent) $\mathrm{x} 2$ (attire) $\mathrm{x} 2$ (job status) ANOVA was conducted to test this research question. Results of the ANOVA revealed only a significant two-way interaction effect for accent and status, $F(1,199)=2.92, \mathrm{p}=.089$. Results of simple effects analyses showed the effect of job status when the job applicant spoke with a standard American English accent, $F(1,203)=2.27, p=.029$, such that the standard American Englishaccented applicant $(M=6.06, S D=.93)$ was recommended more for the low status job than for the high status job $(M=5.58, S D=1.42)$. Table 4 displays the means and 
standard deviations for hiring recommendations as a function of a job applicant's accent and job status. Table 5 shows the summary of the ANOVA. Figure 2 shows the mean hiring recommendation as a function of accent and job status.

Table 4

Means and Standard Deviations for Hiring Recommendations as a Function of a Job Applicant's Accent and Job Status

\begin{tabular}{lcccccccc}
\hline & \multicolumn{3}{c}{ Low-Status } & & & \multicolumn{3}{c}{ High-Status } \\
\cline { 2 - 4 } \cline { 6 - 8 } & $n$ & $M$ & SD & & $n$ & $M$ & $S D$ \\
\hline Standard American English & 51 & 6.06 & 0.93 & & 60 & 5.58 & 1.42 \\
Arabic & 544 & 5.73 & 1.09 & & 52 & 5.87 & 0.94 \\
\hline
\end{tabular}

Table 5

Mean Hiring Recommendation as a Function of a Job Applicant's Accent and Job Status

\begin{tabular}{lcccc}
\multicolumn{1}{c}{ Source } & SS & df & MS & F \\
\hline Accent & .37 & 1 & .37 & .28 \\
Hijab & .32 & 1 & .32 & .25 \\
Job status & 2.39 & 1 & 2.39 & 1.86 \\
Accent x Hijab & .01 & 1 & .01 & .01 \\
Accent x Job status & 3.76 & 1 & 3.76 & $2.92 *$ \\
Hijab x Job status & 1.14 & 1 & 1.14 & .88 \\
Accent x Hijab x Job status & .1 & 1 & .1 & .08 \\
Error & & & & \\
\hline
\end{tabular}

note. $* p<.05$. 


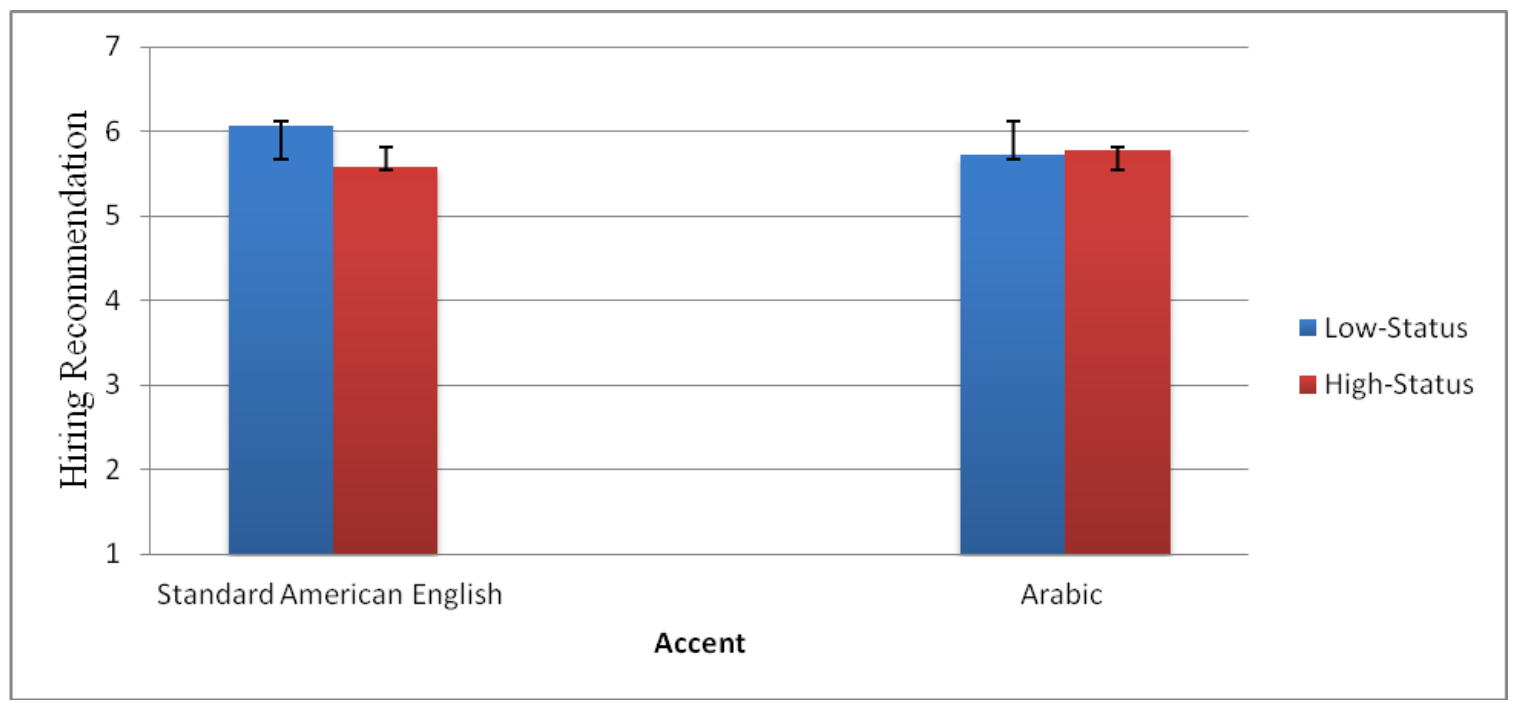

Figure 2. Hiring recommendation as a function of accent and job status

In sum, the results of the present study showed that an Arabic-accented applicant and an applicant wearing a hijab was not rated less competent and warm compared to a standard American English-accented applicant and an applicant not wearing a hijab, respectively. Furthermore, an Arabic-accented applicant wearing a hijab was not perceived as least competent and warm.

However, when it came to suitability ratings, an applicant's accent, attire, and job status all interacted to influence them. When applicants applied for a low status retail sales job, only their accent seemed to influence suitability ratings such that Arabicaccented applicants seemed to be considered less suitable for such a job. However, for the high status retail sales job, both applicants' accent and attire influenced suitability ratings such that when an applicant did not wear a hijab, an Arabic-accented applicant was rated as less suitable for the job compared to a standard American English-accented applicant. When a standard American English-accented applicant applied for the job, those with a hijab were rated as less suitable for the job than those not wearing a hijab. 
However, results pertaining to suitability ratings were not translated into hiring recommendations. The only standard American English-accented applicant was recommended less for the high status job than for the low status job. 


\section{Discussion}

Due to an increasing influx of immigrants, the foreign-born population occupies a sizable proportion of the U. S. labor force. Currently, foreign-born individuals comprise $16.5 \%$ of the U.S. labor force (U.S. Department of Labor, 2014). Although they have become an integral part of the U.S. workforce, research on them is scarce (Bell, Kwesiga, \& Berry, 2010), in particular research on those who speak English with accent. Such research is important because native English speakers often react negatively to foreign accents (Cargile \& Bradac, 2001) and these negative reactions might lead to negative treatment against foreign-accented job applicants and employees. Available but limited empirical evidence shows that there is a bias against those who speak foreign-accented English in the workplace (e.g., Hosoda et al., 2010). For example, foreign-accented applicants are considered less suitable and hired less often than standard American English-accented individuals, especially for high status jobs (e.g., Hosoda et al.).

However, research on foreign accents in the workplace has exclusively focused on the effects of foreign accents on employment-related decisions and neglected to examine how other attributes of immigrants might interact with a foreign accent to influence employment-related decisions. More recently, Deprez-Sims and Morris (2013) called for more studies that would explore the specific conditions under which accent-based biases are present. In response to their call, the present study examined how the additional characteristic of a target with a foreign accent - a hijab - would influence employmentrelated decisions. To study other salient markers such as a hijab is especially important, given that women with a hijab experience a bias in the workplace (Unkelbach et al., 
2010). Furthermore, given the $9 / 11$ terrorist attacks, it is likely that Americans associate those who wear a hijab with the Muslim religion and are likely to have negative attitudes towards individuals who speak with an Arabic accent and who wear a hijab (Lombardo, 2013). Therefore, they are likely to be at a disadvantage upon applying for a job, especially high status job. Thus, the present study examined the interactive effects of a hypothetical applicant's accent (standard American English vs. Arabic) and attire (hijab vs. no hijab), and job status (low vs. high) on perceptions of applicants (e.g., competence, warmth) and employment-related decisions (e.g., suitability ratings, hiring recommendation).

It was hypothesized that (a) Arabic-accented applicants would be perceived less positively on competence (e.g., competence, status) and warmth (e.g., kind, friendly) than standard American English-accented applicants, that (b) applicants who wear a hijab would be perceived less favorably on competence and warmth than non-hijab applicants, and that (c) there would be an interaction between accent and attire on the perceptions of competence and warmth such that Arabic-accented applicants with a hijab would be evaluated least positively on competence and warmth and standard American Englishaccented applicants without a hijab would be rated most favorably on these dimensions. However, the results of the present study did not support any of these hypotheses. An Arabic-accented applicant was not perceived as less competent and warm than the standard American English-accented applicant. Likewise, the applicant with a hijab was not perceived as less competent and warm than the applicant without a hijab. Finally, there was no interaction between accent and hijab on these perceptions. The lack of main 
effects of accent and the presence of a hijab on the perception of competence and warmth are inconsistent with past findings which show that foreign-accented individuals and those with a hijab are seen as less competent and warm than their standard-accented applicants and those without a hijab, respectively.

The lack of these main effects and interaction effect could be due to the location of the study. Given that California has the highest percentage of foreign-born population (27\%) among all the states (U.S. Census Bureau, 2010), it is possible that many of the participants had been exposed to individuals with foreign accents on a regular basis, or that they themselves are the offspring of the individuals with foreign accents. Indeed, about $40 \%$ of the students in the university come from households where English is not the first language (Race to the bottom, 2015). Likewise, the university has an ethnically diverse body of students and faculty. Hence, participants might have had a great amount of positive and close interactions with instructors, professor or other students with accents and/or with a hijab and they have become more receptive to foreign accents and religion, which might have contributed to the lack of negative perceptions against the Arabic accent and an applicant with a hijab. However, this interpretation is speculative and future research should be conducted in a location that has a lower percentage of a foreign-born population.

Research question 1 asked whether the accent and attire of job applicants, and job status would interact to influence job suitability ratings. Although hypotheses pertaining to person perceptions were not supported, there was a significant three-way interaction among accent, attire, and job status on job suitability ratings (i.e., employment-related 
decisions). More specifically, a standard American English-accented job applicant was rated as more suitable than an Arabic-accented applicant for the low status job; however, a standard American English-accented applicant, although not statistically significant, was rated as more suitable than an Arabic-accented applicant for the high status job when they did not wear a hijab. This result is consistent with past findings that show a bias against foreign-accented applicants for high status jobs (e.g., Hosoda et al. 2012). However, because this result was not statistically significant, the result should be interpreted with caution. Furthermore, although not statistically significant, a standard American English-accented applicant without a hijab was rated as more suitable than a standard American English-accented applicant with a hijab for the high status job. This finding might be because many participants identified a standard American Englishaccented applicant with a hijab as a Middle Eastern person, and hence showed a bias against her. Alternatively, given that individuals might view Caucasian individuals who wear a hijab as possible converts, which feeds into existing fears that the Islamic culture tries to change the world according to its rule, instead of assimilating and integrating with existing Western cultures (Unkelbach et al., 2010), participants might have shown a bias against a standard American English-accented applicant with a hijab. Again, because of the lack of statistical significance, this interpretation is speculative.

Taken together, these results seem to indicate that an Arabic accent and a hijab might act as a stigma, resulting in a potential bias against those with an Arabic accent and those with a hijab, especially for a high status retail sales job. Interestingly, results of the present study showed that an Arabic-accented applicant wearing a hijab was not 
necessarily discriminated against. The lack of discrimination against her might be because she possessed two stigmas as opposed to just one. Given that the applicant had two potential stigmas (i.e., foreign accent, hijab), participants might have thought that she must have worked very hard to achieve a 3.4 GPA and earn a relevant college degree on her resume and therefore, they did not rate her unfavorably. However, this interpretation is speculative and more studies on the interactive effects of an accent and a hijab on employment-related decisions are needed.

Research question 2 asked whether the accent and attire of job applicants, and job status would interact to influence hiring recommendation. Results showed that a standard American English-accented applicant was recommended more for the low status job than for the high- status job. Although there seems to be the direction of a bias against an Arabic-accented applicant and an applicant with a hijab for the suitability ratings, such negative ratings were not necessarily translated into recommendation decisions.

\section{Theoretical Implications}

Overall, the results of the present study seem to be consistent with Stone-Romero and Stone's (2007) model of stigmatization. That is, an accent and hijab might serve as stigmas such that these attributes do not fit the ideal prototype (VSI) of an organization, especially for high status jobs. A VSI represents the prototype of the ideal job applicant and/or employee and reflects how he or she should behave or appear in an organizational context. Thus, stigmatized individuals create a discrepancy between the perceived attributes of the job applicant (ASI) and the ideal job applicant (VSI). Therefore, 
applicants who speak with a foreign accent or who wear a hijab might face negative consequences in an employment context for high status jobs.

As previously mentioned, Deprez-Sim and Morris (2013) called for more studies that would explore the specific conditions under which accent-based bias occurs, including the characteristics of a target with an accent, of decision makers, and of organizational context. This study addressed their first recommendation by including another characteristic (hijab) of a target. Although many of the results did not reach statistical significance, results of the present study still encourage future research directed at examining a hijab as an additional characteristic and consider other additional variables such as an abaya which is a robe that covers the entire body except the face and feet often worn by Muslim women.

Interestingly, an Arabic-accent and hijab did not interact to influence decision makers - it seems to have an independent effect. As previously mentioned, perhaps both stigmas together place such an applicant at such a disadvantage that when they meet job qualifications they are perceived as hard working or impressive by decision makers and thus reduce discrimination against them, however, more research is needed to test this assertion.

\section{Practical Implications}

Overall, results showed a direction of bias against Arabic-accented applicants and those applicants who wore a hijab, especially for a high status job. There are several practical strategies that organizations could employ to reduce a bias against stigmatized (i.e., foreign accent, hijab) applicants. Companies might be able to reduce bias by 
providing structured job interviews to applicants (Hosoda \& Stone-Romero, 2010;

Huffcutt, Conway, Roth, \& Stone, 2001). Structured interviews use predetermined questions and hence, have less room for subjective judgment. Second, companies should train human resource employees to conduct interviews in such a manner that they disregard job irrelevant factors (e.g., accent, hijab). Furthermore, companies should teach them how stereotypes could influence their perceptions, attitudes, and behaviors and train them not to rely on stereotypes about job applicants when making employmentrelated decisions. Such individuals are likely to interview candidates impartially and might be able to reduce bias against foreign-accented applicants or applicants who wear a hijab.

\section{Strengths, Limitations, and Future Research}

A major strength of the study is that the present study expanded literature on the effects of foreign accent in the workplace by adding another salient marker - a hijab. To the author's best knowledge, the present study is the first study that examined interactive effects of accent and attire - two visible stigmas - on employment-related decisions. Second, the experimental nature of the present study allowed for experimental control and thus casual inferences could be made. Third, as mentioned previously, the matchedguise technique was used where the speaker was held constant by design. It controls for speaker-specific variables such as pitch or tone that could confound results if two different speakers are used in a study (Gluszek \& Dovidio 2010). However, the matchedguise technique is not without limitations. It might be susceptible to threats to validity that are present when conclusions are drawn about the impact of accent based on single 
empirical realization of it (Cargile \& Giles, 1997). Hence, future studies might use more than one speaker to increase the generalizability of the effects of a foreign accent on employment-related decisions.

Second, the applicant's ethnicity used for both applicants was Caucasian and not Middle Eastern. This could be problematic because the use of only a Caucasian ethnicity does not display the true physical characteristics of a Middle Eastern female. Indeed, Unkelbach et al. (2010) found an interaction effect between the ethnicity of job applicants (Caucasian vs. non-Caucasian) and hijab (hijab vs. no hijab) such that the negative effect of wearing a hijab was stronger for the Caucasian than for non-Caucasian applicants. The negative effect of Caucasian women who wear a hijab could make them appear like converts and therefore triggers fears that individuals who practice Islam seek to go by their religious beliefs and practices and not assimilate to western culture. Future researchers should include both ethnicities.

Third, participants were university students who may not have experience in personnel decision making. Thus, the results of the present study may not be generalizable to those who actually make hiring decisions in organizations. That is, the study was conducted at the university and consisted of college students who were not representative of the workforce. In addition, the younger age group of this sample does not reflect a more mature working population, which typically consists of a wide range of demographics (e.g., age).

Future research should consider sampling actual human resources professionals or hiring managers who make hiring decisions. Sampling a range of organizations along 
with a diverse composition of employees should be considered to avoid bias and such a sample would represent the workplace more accurately. Furthermore, this study examined a foreign accent and included a hijab as an additional salient marker. However, future research should examine other variables such as an abaya to consider other markers that might serve as a stigma and reveal a bias against such individuals.

\section{Conclusion}

Although not statistically significant, the results of the present study show that applicants with an Arabic accent might be discriminated against for a high status retail sales job. Additionally, the present study demonstrates that applicants who wear hijabs might be discriminated against compared to those without hijabs for a high status retail sales job. Interestingly, Arabic-accented applicants wearing hijabs may not be necessarily discriminated against. Future research should include foreign accents along with other salient characteristics of an individual. As previously suggested, organizations should consider structured interviews to decrease potential adverse impact (Hosoda \& Stone-Romero, 2010; Huffcutt et al., 2001). Well-trained and qualified interviewers are equally important to reduce or prevent discrimination such that decision makers judge candidates fairly. Such strategies are likely to yield enormous benefits for an organization and future job candidates. 


\section{References}

Barona, D. B. (2008). Native and non-native speakers' perceptions of non-native accents. Language and Literature Journal, 3. Retrieved March 20, 2011 from http://ojs.gc.cuny.edu/index.php/lljournal/article/view/430/428.

Bell, M. P., Kwesiga, E. N., \& Berry, D. P. (2010). Immigrants: The new invisible men And women in diversity research. Journal of Managerial Psychology, 25, 177188. doi: 10.1108/02683941011019375.

Bureau of Labor Statustucs U.S. Department of Labor (2014). Foreign-born workers: Labor force characteristics - 2014. Retrieved on May 21, 2015 from http://www.bls.gov/news.release/pdf/forbrn.pdf.

Brennan, E., \& Brennan, J. (1981). Accent scaling and language attitudes: Reactions to Mexican American English speech. Language and Speech, 24, 207-221.

Bresnahan, M. J., Ohashi, R., Nebashi, R., Liu, W. Y., \& Shearman, S. M. (2002). Attitudinal and affective response toward accented English. Language \& Communication, 22, 171-185. doi:10.1016/S0271-5309(01)00025-8.

Cargile, A. C., \& Bradac, J. J. (2001). Attitudes toward language: A review of applicantevaluation research and a general process model. In W. B. Gudykunst (Ed.), Communication yearbook 25 (pp. 347-382). Mahwah, NJ: Lawrence Erlbaum.

Cargile, A. C., \& Giles, H. (1997). Language attitudes towards varieties of English: an American- Japanese context. Journal of Applied Communication Research, 26, 338-356. doi:10.1080/00909889809365511.

Caulifield, P. (2011, June 28). Muslim woman, Hani Khan, says Abercrombie \& Fitch fired her for wearing a headscarf. The New York Times. Retrieved fromhttp://www.nydailynews.com/news/national/muslim-woman-hani-khanabercrombie-fitch-fired-wearing-headscarf-article-1.131972.

Center For Immigration Studies (2011). Immigrants in the United States: A Profile of America's Foreign-Born Population. Retrieved on March 2011 from, http://www.cis.org/node/3876.

Deprez-Sims, A., \& Morris, S. B. (2010). Accents in the workplace: Their effects during a job interview. International Journal of Psychology, 45, 417-426. doi: 10.1080/00207594.2010.499950. 
Deprez-Sims, A., \& Morris, S. B. (2013). The effect of non-native accents on the evaluation of applicants during an employment interview: The development of a path model. International Journal of Selection and Assessment, 21, 355-367. doi:10.1111/ijsa.12045.

Fiske, S. T., Cuddy, A. J. C., Glick, P., \& Xu, J. (2002). A model of (often mixed) Stereotype content: Competence and warmth respectively follow from perceived status and competition. Journal of Personality and Social Psychology, 82, 878902. doi:10.1037/0022-3514.82.6.878.

Fuertes, J. N., Gottdiener, W. H., Martin, H., Gilbert, T. C., \& Giles, H. (2012). A metaAnalysis of the effects of speakers' accents on interpersonal evaluations. European Journal of Social Psychology, 42, 120-133. doi. 10.1002/ejsp.862.

Ghumman, S., \& Ryan, A, M. (2013) Not welcome here: Discrimination towards women Who wear the Muslim headscarf. Human Relations, 66, 671-698. doi:10.1177/0018726712469540.

Giles, H., Wilson, P., \& Conway, A. (1981). Accent and lexical diversity as determinants of impression formation and employment selection. Language Sciences, 3, 92-103.

Gluszek, A., \& Dovidio, J. F. (2010). Speaking with a nonnative accent: Perceptions of bias, communication difficulties, and belonging in the United States. Journal of Language and Social Psychology, 29, 224-234. doi:10.1177/0261927X09359590.

Hosoda, M., \& Stone-Romero, E (2010). The effects of foreign accents on employmentrelated decisions. Journal of Managerial Psychology, 25, 113-132. doi:10.1108/02683941011019339.

Hosoda, M., Nguyen, L. T., \& Stone-Romero, E. (2012). The effect of Hispanic accents on employment decisions. Journal of Managerial Psychology, 27, 347-364. doi:10.1108/02683941211220162.

Hosoda, M., Stone-Romero, E. F., \& Walter, J. N. (2007). Listeners' cognitive and Affective reactions to English speakers with standard American English and Asian accents. Perceptual and Motor Skills, 104, 307-326. doi:10.2466/PMS.104.1.307-326.

Huffcutt, A. I., Conway, J. M., Roth, P. L., \& Stone, N. J. (2001). Identification andmetaanalytic assessment of psychological constructs measured in employment interviews. Journal of Applied Psychology, 86(5), 897-913. doi:10.1037/00219010.86.5.897. 
Kalin, R., Rayko, D.S., \& Love, N. (1980). The perception and evaluation of job candidates with four different ethnic accents. In H. Giles, W. P. Robinson, \& P. M. Smith (Eds.), Language: Social Psychological Perspectives (pp. 197-202). Oxford: Pergamon Press.

King, E. B., Ahmad, A. S. (2010). An experimental field study of interpersonal discrimination towards Muslim job applicants. Personnel Psychology, 63, 881906. doi:10.1111/j.1744-6570.2010.01199.x.

Lambert, W. (1967). A social psychology of bilingualism. Journal of Social Issues, 23, 91-109.

Lee, T. L., \& Fiske, S. T. (2006). Not an outgroup, not yet an ingroup: Immigrants in the Stereotype Content Model. International Journal of Intercultural Relations, 30(6), 751- 768. doi:10.1016/j.ijintrel.2006.06.005.

Lombardo, S. (2013, May 3). Muslim American women and a hijab: Dismantling the patronizing narrative. The Northeastern University Political Review. Retrieved। from http://www.nupoliticalreview.com/?p=2079.

Mahmud, Y., \& Swami, V. (2010). The influence of a hijab (Islamic head-cover) on perceptions of women's attractiveness and intelligence. Body Image , 7(1), 90-93. doi:10.1016/j.bodyim.2009.09.003.

Pew Research Center (2007). Muslim Americans: Middle Class and Mostly Mainstream. Retrieved from http://www.pewresearch.org/.

Podberesky, R., Deluty, R., \& Feldstein, S. (1990). Evaluations of Spanish-and Orientalaccented English applicants. Social Behavior \& Personality, 18, 53-63. doi:10.2224/sbp.1990.18.1.53

Post, A. (2012, December 26). Accent-related discrimination suits on the rise, says EEOC. Inside Counsel. Retrieved from http://www.insidecounsel.com/ 2012/12/26/accent-related- discrimination-suits-on-the-rise-sa.

Race to the Bottom. (2015). The price students pay. Retrieved from http://www.calfac.org/sites/main/files/file-attachments/race_to_the_bottom-Stone-S the_price_students_pay.pdf.

Reitz, J. G. (2001). Immigrant success in the knowledge economy: Institutional change and the immigrant experience in Canada, 1970-1995. Journal of Sociallssues, 57(3), 579-613. doi:10.1111/0022-4537.00230. 
Stone-Romero, E. F., \& Liakhovitski, D. (2002). Strategies for detecting moderator variables: A review of conceptual and empirical issues. Research in Personnel Resources Management, 21, 333-372. doi:10.1016/S0742-7301(02)21008-7.

Stone-Romero, E. F., \& Liakhovitski, D. (2002). Strategies for Detecting Moderator Variables: A Review of Conceptual and Empirical Issues. In G. R. Ferris, J. J. Martocchio, G. R. Ferris, J. J. Martocchio (Eds.), Research in Personnel and Human Resources Management (pp. 333-372). US: Elsevier Science/JAI Press. doi:10.1016/S0742-7301(02)21008-7.

Stone-Romero, E. F., \& Stone, D. L. (2007). Cognitive, affective, and cultural influences On stigmatization: Impact on human resource management processes and practices. Research in Personnel and Human Resources Management, 26, 117167. doi:10.1016/S0742-7301(07)26003-7

The United States General Accounting Office. (1990). Immigration Reform: Employer Sanctions and the question of discrimination. (No. 140974). Retrieved on November 15, 2009 from, http://archive.gao.gov/d24t8/140974.pdf.

Unkelbach, C., Schneider, H., Gode, K., \& Senft, M. (2010). A turban effect, too: Selection biases against women wearing Muslim headscarves. Social Psychological and Personality Science, 1(4), 378-383. doi:10.1177/1948550610378381.

U.S. Census Bureau. (2010). The foreign-born population in the United States: 2010. Retrieved from https://www.census.gov/prod/2012pubs/acs-19.pdf. 


\section{Appendix}

Survey Items

\section{Job Suitability}

1. The applicant is qualified for the job.

2. The applicant will be successful on the job.

3. The applicant is able to form a relationship with customers.

4. The applicant is capable of achieving sales goals.

5. The applicant is capable of communicating effectively with customers.

6. The applicant is able to make a connection with customers.

7. The applicant is able to make a lasting impression of the company brand.

8. The applicant is able to engage with customers courteously.

9. The applicant is able to engage with customers professionally.

10. The applicant is able to provide good customer service.

11. The applicant is able to handle irate customers.

12. The applicant is able to work well with other team members.

Decision to hire

1. Definitely not recommend hiring/Definitely recommend hiring

Personal Characteristics (Hosoda \& Stone-Romero, 2010)

1. Educated/Uneducated

2. Upper class/ Lower class

3. Intelligent/Not intelligent

4. White-collar/Blue collar

5. Advantaged/Disadvantaged

6. Warm/Cold

7. Friendly/Unfriendly

8. Likeable/Unlikeable

9. Pleasant/Unpleasant

10. Considerate/Inconsiderate

11. Confident/Not confident

12. Incompetent/Competent 